\title{
Geología, geomorfología y ocurrencia de deslizamientos en la cuenca alta del Río Virilla, Costa Rica
}

\section{Geology, geomorphology and landslide occurrence in the upper Virilla River basin, Costa Rica}

\author{
José María Sequeira-Arguedas ${ }^{1}$ \\ Universidad de Costa Rica, Costa Rica
}

\begin{abstract}
Resumen
El cerro Pico de Piedra constituye una estructura volcánica colapsada del Grupo volcánico Irazú, asociable con el vulcanismo del miembro Paraíso y conforma la cuenca alta del río Virilla. La interpretación por medio de sensores remotos, recopilación bibliográfica, levantamiento geomorfológico y visitas al campo permitieron identificar procesos erosivos intensos en la cuenca, inestabilidad de laderas y susceptibilidad del corredor vial La Holanda que comunica fincas productoras de leche y tubérculos con San Isidro de Coronado. La ocurrencia de deslizamientos y susceptibilidad se evaluó con el método Mora-Vahrson modificado y Probabilistic Infinite Slope Analysis (PISA), modelando diversos grados de saturación en los suelos volcánicos y diversos escenarios, entre ellos los de Patillos de 1952 y Cinchona en 2009. La zonificación geológica integrada en la cuenca sugiere conservar la cobertura forestal actual, controlar la erosión y respetar los retiros respecto a los cauces fluviales. Las áreas agropecuarias actuales son de uso conforme y las más estables en relación a su condición geomorfológica.
\end{abstract}

Palabras clave: Deslizamientos, suelos volcánicos, arrastre de bloques, amenaza sísmica, geomorfología.

\footnotetext{
Abstract

The Cerro de Pico de Piedra (translated as Mount Pico de Piedra) is a collapsed volcanic structure of the Irazú Volcanic Group associated with Paraíso Member's volcanism and constitutes part of

1 Licenciado en Geología, Escuela Centroamericana de Geología, Universidad de Costa Rica, Costa Rica. Correo electrónico: jose.sequeiraarguedas@ucr.ac.cr. (D) https://orcid.org/0000-0003-0767-2929
} 
the upper basin of the Virilla River. Data interpretation gathered by remote sensing, bibliographical compilation, geomorphological survey and field visits allowed the identification of intensive erosion processes, slope instability and hazard (damage) susceptibility of the La Holanda transport corridor (road) that connects milk- and tuber-producing farms with the town of San Isidro de Coronado. Landslide occurrence and transport corridor susceptibility were assessed according to modified Mora-Vahrson and probabilistic infinite slope analysis (PISA) methodologies by modeling various degrees of soil water saturation in volcanic soils under two conditional seismic scenarios referenced to the Patillos (1952) and Cinchona (2009) Costa Rican earthquakes. Integrated geological zoning of the upper basin suggests the need to preserve the current forest coverage, minimize erosion rates and maintain appropriate buffering allowance distances of anthropogenic activities from fluvial bodies. Current agricultural areas are located within the legally established regulated territorial zoning attributed as being the most stable in relation to their geomorphological conditions.

Keywords: Landslides; Volcanic soils; Boulder drag; Seismic hazard; Geomorphology.

\section{Introducción}

El área de estudio se localiza en el cantón Vázquez de Coronado, provincia de San José. Abarca el sector este del distrito de San Rafael, siendo un sector donde se asientan fincas de producción agropecuaria, infraestructura hidráulica de captación y distribución, además se localizan algunas viviendas (Figura 1). En este sector inicia la cuenca del río Virilla y de la quebrada Sangrino, de las cuales se capta agua para algunos poblados del cantón.

Predominan las laderas abruptas, sectores boscosos y pastos dedicados a producción pecuaria y en menor medida a parcelas de cultivo. El punto más elevado es el cerro Pico de Piedra con 2633 m.s.n.m. y constituye una estructura volcánica colapsada asociada al volcanismo del Grupo Irazú (Alvarado et al., 2006, p. 263).

La precipitación anual alcanza los $2500 \mathrm{~mm}$, siendo septiembre y octubre los meses más lluviosos (IMN, 2019), además se presentan suelos descubiertos y evidencias superficiales de inestabilidad en suelos volcánicos.

Los andisoles relacionados al Volcán Irazú (Mata, Rosales, Vásquez \& Sandoval, 2013) presentan texturas franco arenosas a arcillosas, con buena retención de humedad, baja densidad aparente y baja resistencia al corte o cizalle (Henríquez, Cabalceta, Bertsch \& Alvarado, 2014). La fábrica de estos suelos y el intemperismo de materiales volcánicos recientes usualmente genera alófanas y halloysitas, las cuales son 
José María Sequeira-Arguedas

Geología, geomorfología y ocurrencia de deslizamientos en la cuenca alta del Río Virilla, Costa Rica

Figura 1: Uso de la tierra dentro del área de estudio en las cercanías del cerro Pico de Piedra en Vázquez de Coronado, los límites del área y su localización dentro de Costa Rica.

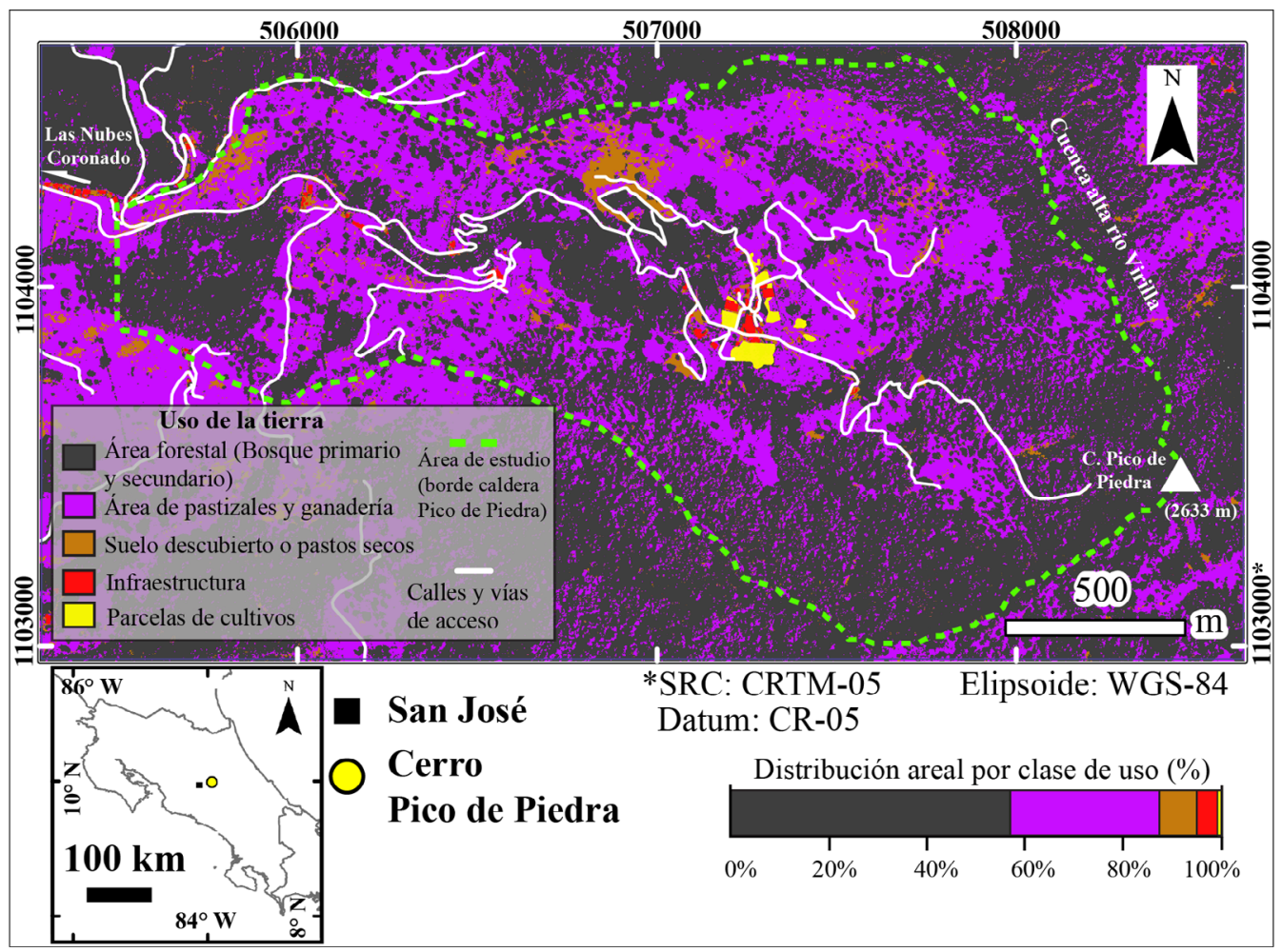

Fuente: Insumos cartográficos IGN (2007) y Sistema Nacional de Información Territorial (2017)

susceptibles ante la erosión hídrica acelerada (Alvarado, Mata \& Chinchi11a, 2014, p. 82 y 86).

Por otra parte, el acceso al sitio se logra por medio de la red vial cantonal (en adelante corredor vial La Holanda), la cual cuenta con un puente de propiedad privada, dos puentes viales cantonales sobre el cauce del río Virilla (P1 y P2), tendidos eléctricos y de telecomunicaciones (Figura 2) susceptibles ante colapsos por procesos de remoción en masa y caída de rocas, principalmente. 
.Figura 2: Mapa inventario de infraestructura en el área de estudio

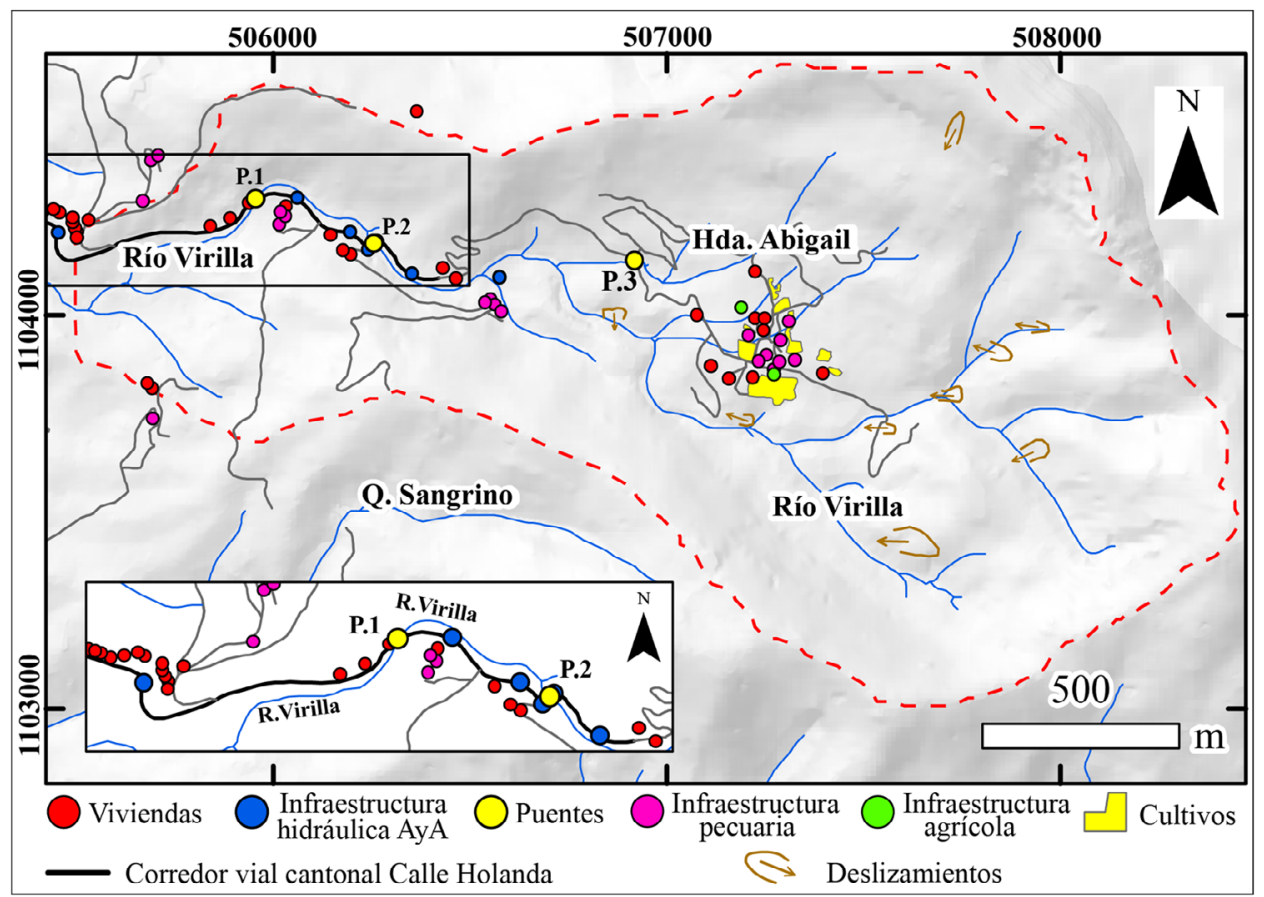

Fuente: Elaboración propia

Adicionalmente, el inventario de infraestructura indica una calzada vial con un ancho de $4 \mathrm{~m}$ (líneas negras y grises Figura 2), cinco tanques de captación y sus tuberías pertenecientes al Instituto Costarricense de Acueductos y Alcantarillados (AyA), y más de cincuenta inmuebles entre viviendas, almacenes, graneros y lecherías.

\section{Contexto geológico y sísmico}

En primera instancia, Bergoeing (1979, p. 139 y 140) identifica una estructura volcánica que denominó volcán Las Nubes, que consiste de un antiguo cráter erosionado en el extremo oeste (Figura 1).

Vargas (1994, p. 37 y 38) estudia el área con fines hidrogeológicos determinando que las rocas aflorantes en el área de estudio son basaltos y andesitas con augita asociados con el Grupo Aguacate. Sin embargo, investigaciones como Alvarado (1993) y Alvarado et al. (2006, p. 264) 
describen la Unidad Pico de Piedra con una edad de 569 ka (Chibaniano) y que constituye las rocas más antiguas sobre las que evolucionó el estratovolcán actual Irazú. Se trata de andesitas y andesitas basálticas con alteración hidrotermal severa que afloran en valles fluviales, algunos puntos de las colinas y en el cerro Pico de Piedra, donde la cobertura de suelos es escasa.

La Unidad Pico de Piedra es considerada como parte de la Formación Reventado (etapa temprana del volcanismo del Irazú) y a su vez dentro de todos los depósitos, piroclastos y lavas del Grupo Irazú (Krushensky, 1972), que cubren el sector norte de la provincia de Cartago, así como el margen sureste y este del cantón de Vázquez de Coronado (Figura 3).

Sobreyaciendo estas rocas y depósitos se identifican cenizas recientes y tobas sin diferenciar que se extienden desde el foco eruptivo del Irazú alcanzando localidades como Platanares de Moravia, San Isidro, Cascajal, y Las Nubes de Coronado (Vargas, 1994, p. 43; Denyer \& Arias, 1991a, p. 45 y 46). La alteración de estos materiales ha generado la cobertura de suelo actual.

Otras hipótesis como la planteada por Hidalgo, Linkimer \& Alvarado (2004, p. 106), determinan que la abertura al oeste de la estructura volcánica Pico de Piedra y la estructura Cabeza de Vaca se asocian con un evento o serie de eventos de colapso gravitacional, cuyos depósitos alcanzaron el Valle Central como avalanchas (debris avalanches/debris flows) de rocas y partículas finas, cargadas en agua y constituyeron el "aglutinante" de los materiales, expuestos en la mayoría de cauces fluviales del Valle Central (Figura 3).

Se identifican otras rocas en el margen oeste de la Figura 3 que forman parte de la Paleo-Cordillera, la cual incluye los antiguos complejos volcánicos del Grupo Volcánico Zurquí (Obando, 2004, p. 84 y 85; Kussmaul, 2000, p. 83 y 84), anteriores a los volcanes actuales de la Cordillera Volcánica Central. En el margen este por su parte, afloran rocas contemporáneas a las del área de estudio asociadas al volcán Turrialba, entre ellas lavas y piroclastos (Alvarado et al., 2006, p. 263; Kussmaul, 2000, p. 83 y 84). 
Figura 3: A) Contexto geológico regional del área de estudio dentro del Grupo Irazú. SFBH: Sistema fallas Bajo La Hondura, SFRS: Sistema fallas Río Sucio, FAG: Falla Alto Grande, FB: Falla Blanquito, FLi: Falla Liebres, FI: Falla Irazú, FL: Falla Lara, FC: Falla Cipreses. B) Unidades litológicas locales identificadas dentro de la estructura volcánica Pico de

\section{Piedra.}

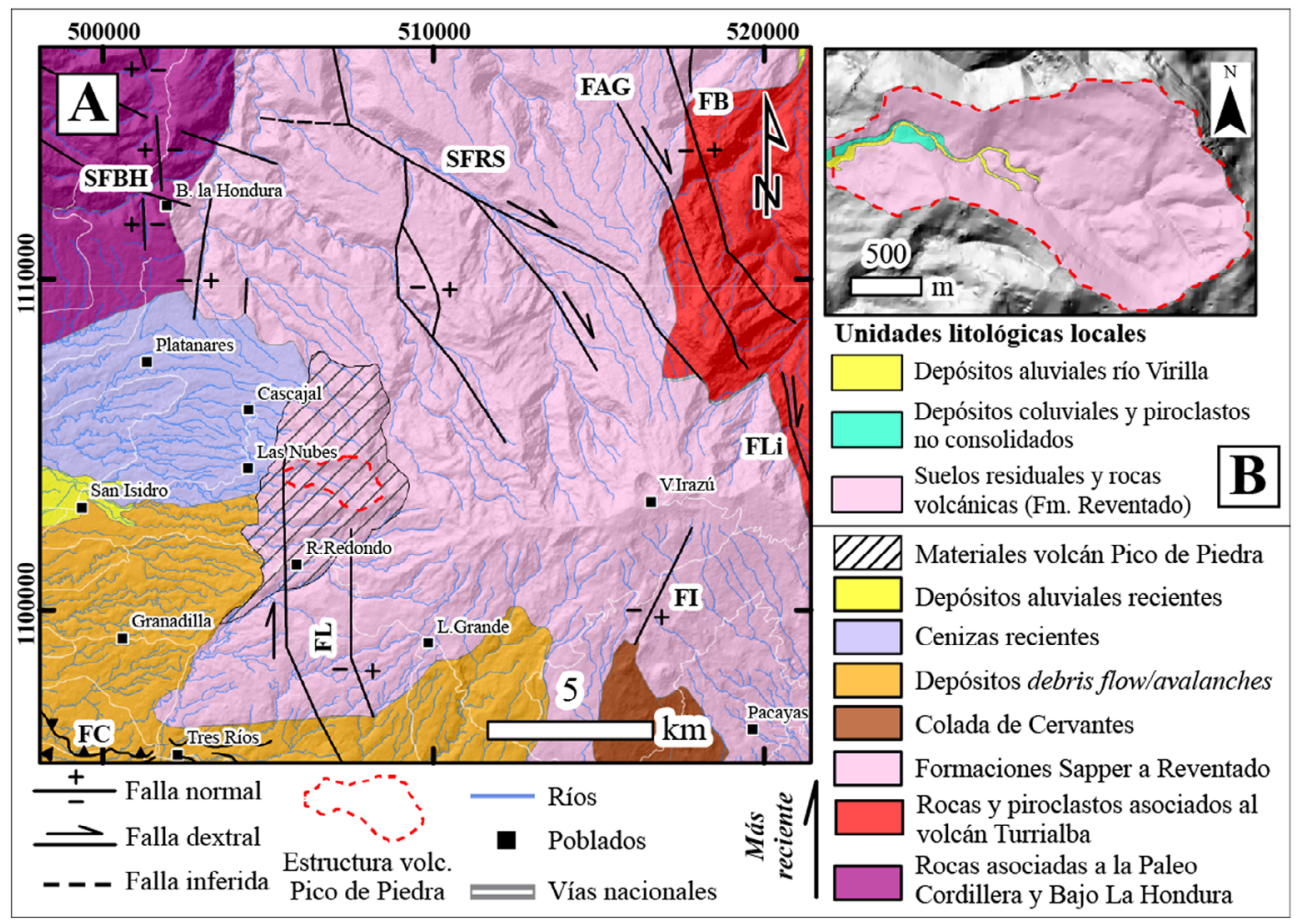

Fuente: Alvarado et al. (2006), Bergoeing (1979), Hidalgo, Alvarado \& Linkimer (2004), ITCR (2014), Linkimer (2003), Montero \& Alvarado (1995), Montero et al. (2013), Rodríguez, Linkimer \& Montero (2019) y Vargas (1994)

Tectónicamente, el sitio es muy dinámico y presenta varias fallas activas a las cuales se les ha atribuido sismicidad histórica e instrumental (Montero \& Alvarado, 1995, p. 28 y 29; Peraldo y Montero, 1999). Según Montero et al. (2013, p. 868) las fallas del flanco norte del volcán Irazú conforman el Cinturón Deformado del Centro de Costa Rica y han causado sismos destructivos atribuidos al Sistema de Fallas Río Sucio y Lara, respectivamente (Figura 3). 
Estos sismos han alcanzado intensidades Mercalli Modificadas de hasta IX (Montero \& Alvarado, 1995, p. 30; Peraldo y Montero, 1999, p. 228) o aceleraciones espectrales estimadas de hasta $2,1 \mathrm{~m} / \mathrm{s}^{2}(21 \%$ de $g)$ según modelos empíricos de intensidad (Linkimer, 2008, p. 84).

Desde la amenaza símica, el registro más lamentable es el impacto que generó el Terremoto de Patillos del 30 de diciembre de 1952 en el Sistema de Fallas Río Sucio, causando 21 muertes, un impacto geológico y geotécnico amplio en el área mesosísmica, como deslizamientos, inestabilidad en estructuras y flujos de lodo, impactando localidades como Cascajal, El Naranjo, Tierras Morenas, Rancho Redondo y San Isidro (Montero \& Alvarado, 1995, p. 31; La Nación, 1953, p. 6). Otro evento es el Terremoto de San Antolín, Cartago de 1841 que generó 22 muertes, destrucción masiva en Cartago y deslizamientos importantes en las localidades de Vázquez de Coronado y Goicoechea, asociándose según descripciones históricas con la Falla Lara (Peraldo y Montero, 1999, p. 227).

Por tanto, son las fallas Río Sucio y Lara principalmente, las que pueden generar sismos que disparen inestabilidad de laderas, caída de rocas o flujos de lodo como se han reportado históricamente para el cauce del río Virilla (Alvarado, 2011, p. 257).

\section{Metodología}

Considerando el contexto geológico y de amenaza sísmica e hidrológica en la cuenca alta del río Virilla, se enfatizó en caracterizar los procesos de geodinámica externa, entre ellos la ocurrencia de deslizamientos e inventariado de deslizamientos actuales.

Para esto se empleó teledetección, vistas al campo, caracterización geomorfológica del área, así como el modelado de susceptibilidad y estabilidad de laderas en la cuenca a partir de la metodología Mora-Vahrson modificada (Mora, Vahrson \& Mora, 1992) y Probabilistic Infinite Slope Analysis (PISA) propuesta por Haneberg (2005). Los insumos geográficos empleados fueron la cartografía a escala 1:10.000 del Instituto Geográfico Nacional (IGN), las ortofotos del Sistema de Información Territorial (SNIT) a escala 1: 5.000 de 2017. El manejo e interpretación de insumos y datos espaciales se realizaron en el software ArcGIS y QGis.

La escogencia de estas metodologías para estimación de ocurrencia de deslizamientos, permite comparar las áreas susceptibles y con 
probabilidad de afectación, ya que en el caso de la metodología MoraVahrson Modificada (MVm), la asignación de pesos y sus parámetros se asignan con categorizaciones cualitativas a criterio de experto y por su naturaleza no considera elementos de probabilidad ni aproxima algún factor de seguridad al sector en estudio (p.e. Mora, Chávez \& Vázquez, 2002).

La metodología PISA permite incorporar parámetros geotécnicos de materiales y considera un coeficiente sísmico de diseño, por lo que determina en condiciones estáticas y pseudoestáticas el factor de seguridad de la ladera por unidad de área (pixel) y la probabilidad de excedencia de aceleraciones críticas del suelo; sin embargo, posee algunas limitaciones que se discutirán posteriormente.

El pixel en este caso tiene una resolución de 1,5 m en dependencia de la información topográfica disponible, por lo que los parámetros restantes de las metodologías MVm y PISA se ajustan al menor tamaño de celda posible, inclusive las estimaciones de intensidad sísmica e hidrológica.

La aplicación de ambas metodologías en la cuenca alta de río Virilla, constituye una oportunidad comparativa muy particular para estimar la afectación por procesos de remoción en masa en un ambiente cerrado y controlado, como lo es la estructura volcánica Pico de Piedra.

La metodología Mora-Vahrson modificada (Mora, Vahrson \& Mora, 1992) es un método heurístico que considera a priori cinco elementos parámetros para la estimación de susceptibilidad al deslizamiento, valiéndose de mapas geológicos, humedad del suelo, pendiente del terreno y disparo por sismos o lluvias intensas para un periodo de retorno de 100 años. Por tanto, requiere de instrumentación meteorológica cercana, registros sísmicos históricos y caracteriza el grado de susceptibilidad $(\mathrm{H})$ en muy alta, alta, moderada, baja y muy baja (Fórmula 1).

$$
H=\left(S_{S} * S_{l} * S_{h}\right) *\left(T_{S}+T_{r}\right) \quad[1]
$$

Donde:

Ss: Susceptibilidad por pendiente

S1: Susceptibilidad litológica

Sh: Susceptibilidad por humedad del suelo anual

Ts: Disparo por sismo

Tr: Disparo por lluvia (Duración: 60 min Tretorno= 100 años) 
Las pendientes se obtuvieron a partir de datos topográficos del IGN, mientras que datos de humedad del suelo y disparo por lluvia se obtuvieron de registros abiertos del CATIE y del Instituto Meteorológico Nacional (IMN). Algunos casos exitosos de aplicación en Costa Rica se presentan en Segura, Badilla \& Obando (2011), Mora, Chávez \& Vázquez (2002), Barrantes, Barrantes \& Núñez (2011) y Quesada \& Feoli (2018, p. 34). Para el detalle de puntuación por parámetro puede consultarse Segura, Badilla \& Obando (2010, p. 106-114); respecto a los parámetros empleados en esta investigación se especifican en el Cuadro 1, considerando intensidades sísmicas similares a las del Terremoto de Patillos de 1952.

Cuadro 1. Parámetros empleados del método MVm en las unidades litológicas identificadas.

\begin{tabular}{ccc}
\hline Parámetros de entrada & Descripción & $\begin{array}{c}\text { Valor } \\
\text { asignado }\end{array}$ \\
\hline $\begin{array}{c}\text { Susceptibilidad por pen- } \\
\text { diente }(\mathrm{Ss})\end{array}$ & De $0^{\circ}$ a $71^{\circ}$ & $\mathbf{0 ~ a ~ 6}$ \\
\hline $\begin{array}{c}\text { Susceptibilidad litológica } \\
\left(\mathrm{S}_{1}\right)\end{array}$ & $\begin{array}{c}\text { Suelos volcánicos regolíticos, rocas volcánicas } \\
\text { andesíticas y piroclásticas, coluviones y depósitos } \\
\text { aluviales. Nivel freático alto (Figura 3 B). }\end{array}$ & $\mathbf{3 , 4}$ y $\mathbf{5}$ \\
\hline $\begin{array}{c}\text { Susceptibilidad humedad } \\
\text { suelo }\left(\mathrm{S}_{\mathrm{h}}\right)\end{array}$ & $\begin{array}{c}\text { Anual, estaciones cercanas IMN. } \\
\text { De 2325 a 2630 mm. }\end{array}$ & $\mathbf{3}$ \\
\hline Disparo por sismo (Ts) & IMM = VIII, aceleración pico $=\mathbf{0 , 2 1 \%} \mathbf{g .}$ & $\mathbf{6}$ \\
\hline Disparo por lluvia (Tr) & $\begin{array}{c}\text { Duración 60 min, } \mathrm{T}_{\text {retorno }}=100 \text { años. } \\
\text { Estación CATIE }(1949-2016) .\end{array}$ & $\mathbf{4}$ \\
\hline
\end{tabular}

Fuente: Mora, Chávez \& Vázquez (2002), Sequeira-Arguedas (2019), IMN (2019) y Montero \& Alvarado (1995)

La metodología Probabilistic Infinite Slope Analysis (PISA) considera para sus cálculos la ecuación del talud infinito (Haneberg, 2005, p. 14), por tanto solo considera espesores deslizables de suelo y rocas como láminas o fallas planares (González de Vallejo, Ferrer, Ortuño \& Oteo, 2002, p. 440 y 447-449). Es una metodología predictiva que presenta fundamento geomorfológico, geotécnico y sobretodo estadístico para la asignación del factor de seguridad en condiciones estáticas o la probabilidad de excedencia de las aceleraciones críticas de Newmark (el suelo alcanza un factor de seguridad $\leq 1,0$ ) en caso de considerarse un sismo de diseño (Fórmulas 2, 3 y 4). 
De acuerdo con la distribución estadística de cada variable aleatoria o parámetro que conforman la ecuación del talud infinito (Fórmula 2), se emplean aproximaciones e iteraciones generadas con estimación inferencial puntual (First Order Second Moment) de los estadísticos de la muestra (parámetros), aproximando una iteración de Montecarlo para un estadístico buscado (media aritmética del FS).

Se genera un archivo espacial ráster (grid file) de estabilidad en términos del factor de seguridad (FS) o probabilidad de excedencia de una aceleración pico dada (PGA) bajo condiciones estáticas y pseudoestáticas (Fórmulas 3 y 4) para cada unidad geotécnica del área, el cual es desplegable en cualquier sistema de información geográfica (SIG). Este análisis no considera falla de la ladera por deslizamientos rotacionales o mecanismos compuestos y la Figura 4 ejemplifica el elemento de suelo o roca deslizable que considera la metodología PISA.

$$
\begin{gathered}
F S=\frac{C_{r}+C_{s}+\left[q_{t}+\gamma_{m} D+\left(\gamma_{s a t}-\gamma_{w}-\gamma_{m}\right) H_{w} D\right] \cos \beta \tan \varphi}{\left[q_{t}+\gamma_{m} D+\left(\gamma_{s a t}-\gamma_{m}\right) H_{w} D\right] \cos \beta \sin \beta} \\
a_{c r i t}=(F S-1) g \sin \beta \\
P\left[a_{N} \leq a_{C r i t}\right]=F\left[a_{N}\left(a_{\text {Crit }}\right)\right]
\end{gathered}
$$

Las ventajas de este método, es que permite incorporar parámetros geotécnicos, asignar carga y cohesión de la vegetación, además de que puede modelarse cualquier escenario de saturación del suelo (seco, semisaturado y saturado) y cualquier evento sísmico (\% de $g$ ) a partir de un coeficiente de aceleración pico o sostenida. Algunos casos exitosos de aplicación de la metodología PISA son Mora (2010, p. 48 y 49), Granados (2013), Quirós (2019) y Carrillo (2019, p. 104). A nivel internacional se tienen investigaciones como Griffits, Huang \& Fenton (2011).

El rango de variación por parámetro se recopiló en literatura a nivel nacional e internacional, empleando una media y su desviación estándar para cada unidad geotécnica (Cuadro 2). Las unidades empleadas son las establecidas por el Sistema Internacional de Unidades (SI). 
Figura 4. Elemento de suelo o roca deslizable considerado en la ecuación del talud infinito.

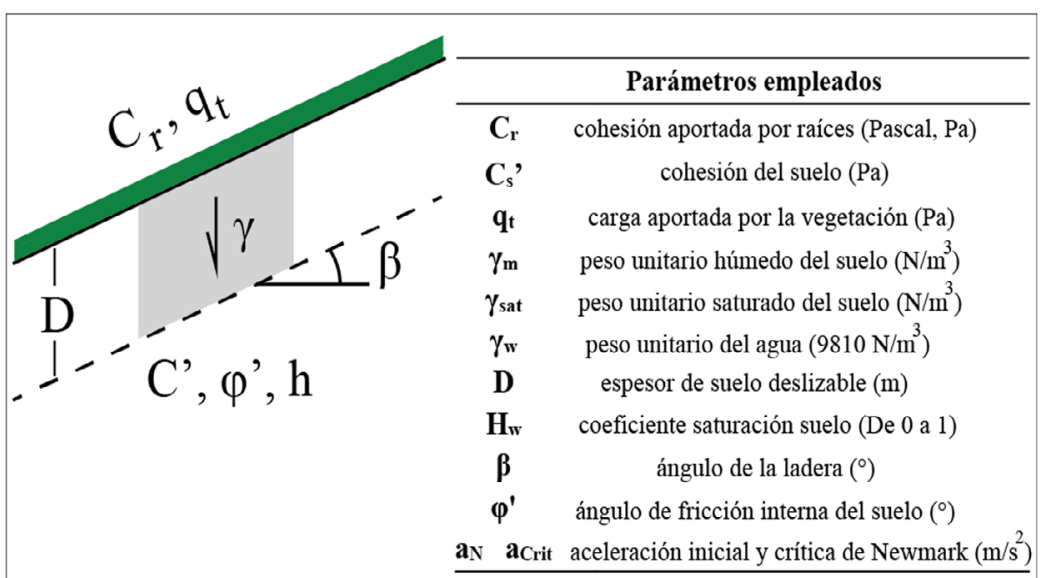

Fuente: González de Vallejo et al. (2002) y Haneberg (2005)

Cuadro 2. Parámetros empleados del método PISA para las unidades geotécnicas identificadas.

\begin{tabular}{|c|c|c|c|}
\hline Parámetro & Rangos considerados & $\begin{array}{c}\text { Distribución } \\
\text { estadística }\end{array}$ & Referencia \\
\hline $\mathrm{C}_{\mathrm{r}}(\mathrm{Pa})$ & $\begin{array}{l}\text { Entre } 0 \text { y } 3000 \text { Pa (bosque pe- } \\
\text { renne y coníferas en suelos de } \\
\text { montaña) }\end{array}$ & Uniforme & López et al. (2008) \\
\hline $\mathbf{q}_{\mathrm{t}}(\mathrm{Pa})$ & $\begin{array}{c}\text { De } 0 \text { a } \mathbf{0 , 0 6 6} \mathbf{P a}(57 \% \text { área de } \\
\text { bosques) Media: } \mathbf{0 , 0 3 3 5} \mathbf{P a} \\
\text { Árboles de } 4 \text { a } 6 \text { m altura } \\
\end{array}$ & Triangular & López et al. (2008) \\
\hline$\gamma_{\mathrm{m}}\left(\mathbf{k N} / \mathbf{m}^{3}\right)$ & $\begin{array}{c}13700 \pm 2400 \text { (Unidad SV) } \\
19120 \pm 3220 \text { (Coluviones) } \\
18850 \pm 3220 \text { (Aluvión) } \\
\end{array}$ & Normal & $\begin{array}{l}\text { Mora (1998), Granados } \\
\text { (2013), Jiménez et al. } \\
\text { (2014a , 2014b) }\end{array}$ \\
\hline$\gamma_{\mathrm{sat}}\left(\mathbf{k N} / \mathbf{m}^{3}\right)$ & $\begin{array}{c}15600 \pm 1700 \text { (Unidad SV) } \\
20340 \pm 2900 \text { (Coluviones) } \\
20140 \pm 2900 \text { (Aluvión) } \\
\end{array}$ & Normal & $\begin{array}{c}\text { Mora (1998), Granados } \\
(2013) \text {, Jiménez et al. } \\
\left(2014^{\mathrm{a}}, 2014 \mathrm{~b}\right)^{*}\end{array}$ \\
\hline$\gamma_{w}\left(\mathbf{N} / \mathbf{m}^{3}\right)$ & $9810 \mathrm{~N} / \mathrm{m}^{3}$ & Constante & - \\
\hline $\mathbf{D}$ & Media: $7 \pm 5 \mathrm{~m}$ & Normal & Inspección en campo \\
\hline $\mathbf{H}_{\mathrm{w}}$ & De 0 a $100 \%(0$ a 1$)$ & Uniforme & $\begin{array}{c}\text { Asignación } \\
\text { determinística }\end{array}$ \\
\hline $\boldsymbol{\beta}$ & Curvas de nivel cada $5 \mathrm{~m}$ & Variable & Curvas de nivel I.G.N. \\
\hline $\mathrm{C}_{\mathrm{s}}{ }^{\prime}(\mathbf{P a})$ & $\begin{array}{c}6000 \pm 6000(\text { Unidad SV) } \\
113700 \pm 113700 \text { (Coluviones) } \\
29400^{\circ} \pm 20000 \text { (Aluvión) }\end{array}$ & Normal & $\begin{array}{l}\text { Mora (1998), Granados } \\
\text { (2013), Jiménez et al. } \\
\left(2014^{\mathrm{a}}, 2014 \mathrm{~b}\right)^{*}\end{array}$ \\
\hline
\end{tabular}


José María Sequeira-Arguedas Geology, geomorphology and landslide occurrence in the upper Virilla River basin, Costa Rica

\begin{tabular}{cccc}
\hline Parámetro & Rangos considerados & $\begin{array}{c}\text { Distribución } \\
\text { estadística }\end{array}$ & Referencia \\
\hline $\boldsymbol{\varphi}$, & $\begin{array}{c}33^{\circ} \pm 6,7^{\circ}(\text { Unidad SV) } \\
25.7^{\circ} \pm 10^{\circ}(\text { Coluviones) } \\
26,7^{\circ} \pm 9,71^{\circ} \text { (Aluvión) }\end{array}$ & Normal & $\begin{array}{c}\text { Mora (1998), Granados } \\
(2013), \text { Jiménez et al. } \\
\left(2014^{\mathrm{a}}, 2014 \mathrm{~b}\right) *\end{array}$ \\
\hline \multirow{2}{*}{$\mathbf{a}_{\mathrm{n}}$} & $\begin{array}{c}0 \text { hasta } 0,21 \% \text { de g } \\
\left(\mathbf{2 , 0 6} \mathbf{~ m} / \mathbf{s}^{2}\right)\end{array}$ & Constante & $\begin{array}{c}\text { Datos LIS, Montero \& } \\
\text { Alvarado (1995), Lin- } \\
\text { kimer (2008) }\end{array}$ \\
\hline
\end{tabular}

Fuente: Unidades geotécnicas basadas en Sequeira-Arguedas (2019) y Mora (1998)

Respecto a la evaluación ante flujos de lodo y avenidas extraordinarias, se recorrió el cauce del río Virilla para las secciones cercanas al corredor vial La Holanda y se evaluó la granulometría de los depósitos, discriminando una zona de influencia a partir de la morfología del cauce y alcance de depósitos de inundación. No se realizó un análisis hidrológico exhaustivo.

\section{Resultados y discusión \\ Geomorfología}

La cuenca en estudio presenta un perímetro de 7,97 km, 2,88 $\mathrm{km}^{2}$ de área, largo de 2,96 km y un ancho máximo de 1,62 km. El sitio presenta morfologías volcánicas con predominancia de pendientes altas (en algunos sectores hasta $70^{\circ}$ ), además de evidencias de inestabilidad como reptación, deslizamientos superficiales, deslizamientos antiguos y afloramiento de depósitos coluviales en inspecciones de campo, las cuales se clasifican como formas de origen denudacional (Figura 5 y 6 ).

Además se identificaron, formas fluviales asociadas a la dinámica del río Virilla y sus tributarios, generando pequeñas áreas de deposición fluvial y arrastre de bloques rocosos.

La evolución de la estructura volcánica Pico de Piedra generó las morfologías de escarpes, colinas volcánicas de moderada y alta pendiente, además del cono intracratérico secundario, localizado en el extremo sureste del área de estudio (Fig. 5).

Estas unidades presentan patrones de drenaje paralelos y diversos grados de disección, alcanzando profundidades de drenajes de hasta $70 \mathrm{~m}$, aunque la disección es mayor en los valles externos a la cuenca del Virilla.

Las colinas con pendientes superiores a $35^{\circ}$ usualmente presentan reptación, divisorias agudas y deslizamientos superficiales recientes, además en época lluviosa se activan cauces ocasionales que arrastran material 
hacia los valles fluviales o son depositados en las zonas de piedemonte o de transición (Figura 6). La erosión es intensa y deja algunos afloramientos del macizo rocoso, variando el perfil de suelo entre 1 y $12 \mathrm{~m}$ de espesor.

Las terrazas intracratéricas son remanentes de coladas de lava y piroclastos de la Formación Reventado, que por su grado de alteración y morfografía pueden asociarse a uno o varios eventos volcánicos, presentando pendientes promedio de $15^{\circ}$ en las secciones de rellanos y pendientes de $45^{\circ}$ o más en los escarpes. Presentan reptación y son empleadas para ganadería.

Las formas denudacionales son las modeladoras del relieve actual en la cuenca alta del río Virilla, ya que se idenficaron al menos tres deslizamientos antiguos con coronas de $200 \mathrm{~m}$ de ancho y depósitos remanentes, además de nueve deslizamientos activos de anchos inferiores a $60 \mathrm{~m}$ concentrados en las cercanías de los valles fluviales.

Adicionalmente, se identifica un cerro disectado en el sector central de la cuenca cuyo modelado se atribuye a agentes hídricos que aceleraron la meteorización química en las rocas, aunque su génesis también puede asociarse a colapsos gravitacionales que aceleraron el proceso de disección.

Los depósitos de piedemonte se localizan en las zonas deprimidas cercanas a los escarpes volcánicos, presentando ondulaciones tipo hummocky, bloques angulosos métricos inmersos en suelo, alcanzando el corredor vial La Holanda y el drenaje de la cuenca (Figura 6).

En el caso de las morfologías fluviales, se restringen a los talweg del río Virilla. En los sectores de mayor elevación se presentan valles en "V" con secciones de hasta $25 \mathrm{~m}$ de ancho, mientras que en los sectores más bajos predominan valles fluviales con secciones transversales de hasta 60 $\mathrm{m}$ de ancho y sectores inundables. En este sector se reconocieron entre uno $\mathrm{y}$ tres niveles de terrazas fluviales apareadas las cuales presentan alturas entre $75 \mathrm{~cm}$ y 1,5 m (Figura 7). Los depósitos presentan imbricación y soporte por matriz arenosa.

Sin embargo, se localizaron bloques erráticos y vegetación arrastrada en los rellanos de las terrazas (Figura 7), por lo que estos sectores son muy dinámicos y dependen de la escorrentía en la cuenca, particularmente en los sectores más elevados. 
Figura 5. Mapa de unidades geomorfológicas identificadas para el área de estudio. Los triángulos amarillos denotan facetas triangulares estructurales inferidas.

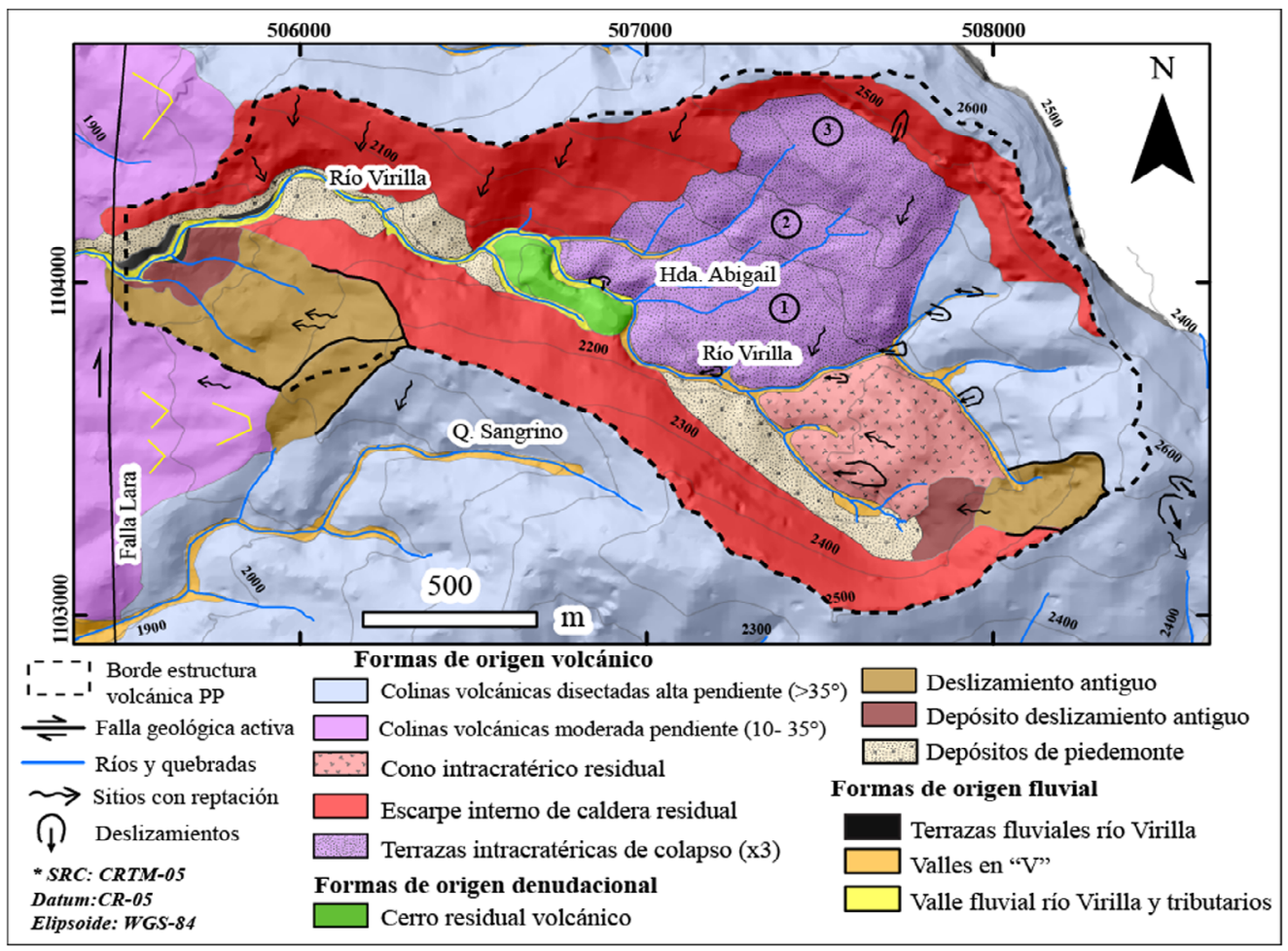

Fuente: Elaboración propia

\section{Mora-Vahrson modificado}

La susceptibilidad ante deslizamientos en la cuenca alta del río Virilla según la metodología Mora-Vahrson modificada permite evaluar de manera relativa los sectores más inestables. La inestabilidad es más extendida en los sectores de mayor pendiente si se considera un sismo con intensidades Mercalli Modificadas de VIII (Figura 8), ya que bajo una precipitación atípica de hasta $368 \mathrm{~mm}$ en una hora, la mayoría del área se clasifica como de susceptibilidad moderada y escasos sectores como de baja, relacionado al efecto de la pendiente. 
José María Sequeira-Arguedas

Geología, geomorfología y ocurrencia de deslizamientos en la cuenca alta del Río Virilla, Costa Rica

Figura 6. A) y B) Vista del escarpe volcánico, las zonas de deposición coluvial y cauces ocasionales. C) Escarpe volcánico de $150 \mathrm{~m}$ y coronas de deslizamiento observadas.

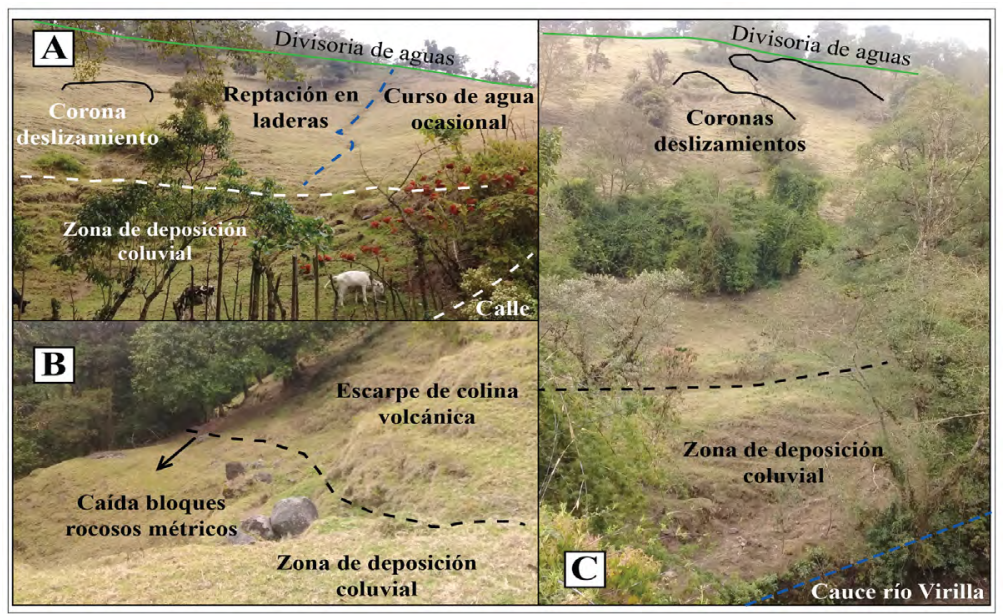

Fuente: Elaboración propia

Figura 7. A) Niveles de terrazas aluviales en el margen izquierdo del río Virilla (aguas abajo). B) Vista de los materiales arrastrados por el río. C) Vista de la granulometría típica de depósitos aluviales en niveles antiguos. D) Vista de niveles más antiguos de terrazas.

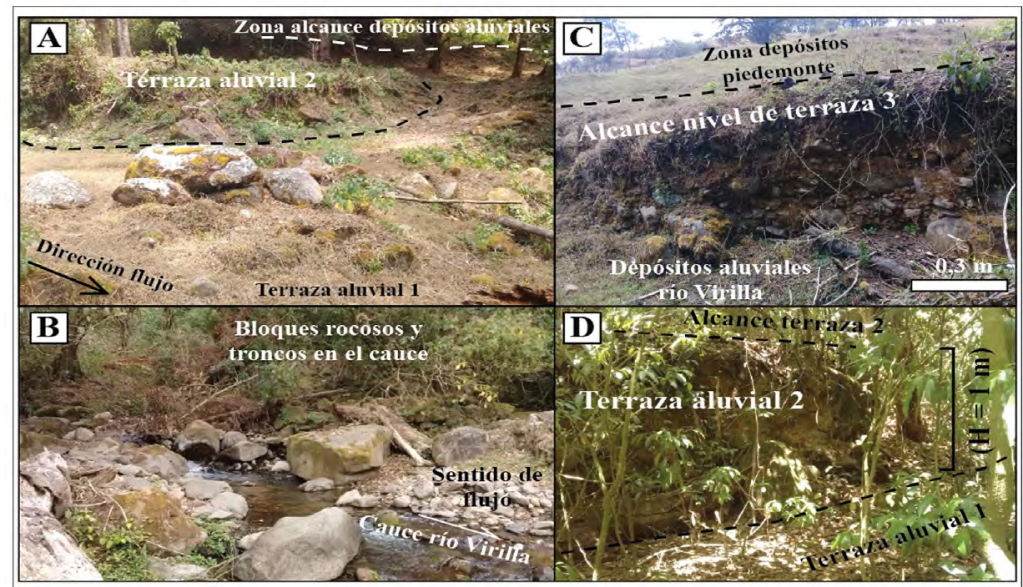

Fuente: Elaboración propia 
Existe un escenario crítico si sucede un sismo cercano como el evento de Patillos de 1952 y si los suelos se encuentran saturados (p.e. entre septiembre a diciembre), ya que en los escarpes y terrazas volcánicas la susceptibilidad es muy alta. Otros sectores en la cuenca se clasifican como de alta y moderada susceptibilidad en función de los parámetros del método (Fig. 8), siendo susceptibles las áreas de deslizamientos antiguos.

Un sismo localizado en la Falla Lara sería un escenario crítico, pues su cercanía podría generar aceleraciones en el suelo superiores a las fuerzas estabilizadoras intrínsecas de los materiales, ya que este escenario es posible considerando la Falla Lara como el foco del sismo de San Antolín, Cartago de 1841 (Peraldo \& Montero, 1999, p. 227 y 228), el cual generó deslizamientos considerables en la región.

Figura 8. Susceptibilidad al deslizamiento en la cuenca alta del río Virilla, según la metodología Mora-Vahrson modificada.

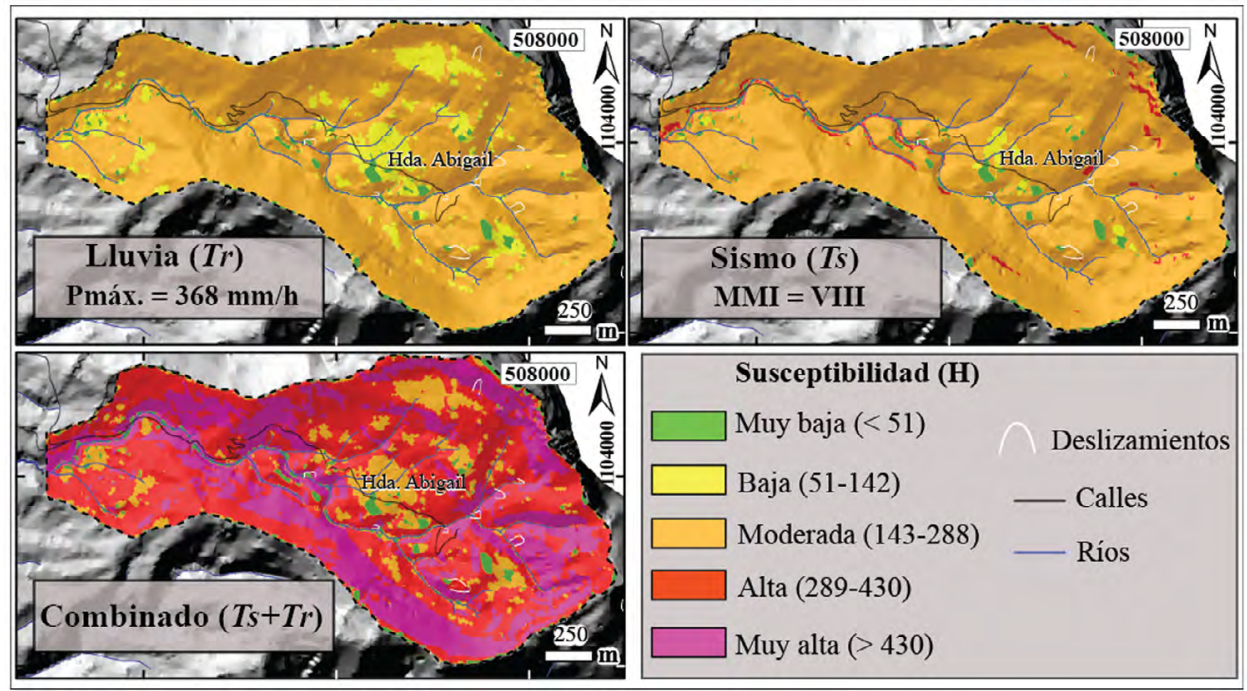

Fuente: Sequeira-Arguedas (2019)

\section{Probabilistic Infinite Slope Analysis (PISA)}

Considerando los modelos de estabilidad y con las propiedades geotécnicas y físico-mecánicas de las unidades geotécnicas (Fig. 3B): A) suelos volcánicos poco a moderadamente compactos (SV), B) aluviones con matriz arenosa, C) Coluviones y material piroclástico suelto; (Cuadro 
2); se decidió emplear un escenario en condiciones sin sismo (estáticas), un escenario con suelo saturado, otro con un sismo lejano en el arco volcánico similar al evento de Cinchona de $2009 \mathrm{y}$ otro con un sismo cercano con aceleraciones críticas de hasta $2,06 \mathrm{~m} / \mathrm{s}^{2}$ (206 Gal) con similitudes al sismo de Patillos.

Figura 9. Media del factor de seguridad en las laderas en condiciones de suelo seco y saturado y su grado de estabilidad asociado, empleando la metodología PISA.

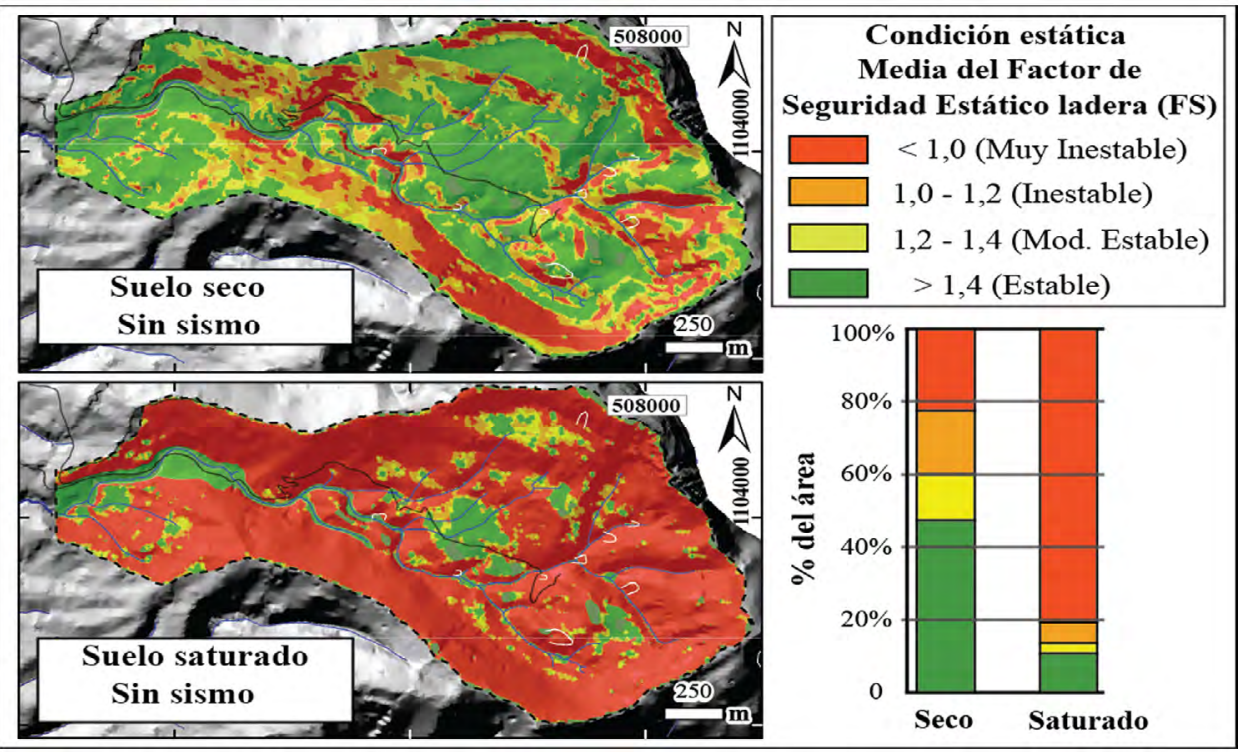

Fuente: Sequeira-Arguedas (2019)

En condiciones estáticas (Figura 9) es notorio que las zonas inestables se restringen a los escarpes ( $23 \%$ de área), que por su condición geomorfológica, poseen pendientes mayores al ángulo de fricción interno de los materiales, manteniendo una similitud con el caso de disparo por sismo de la metodología Mora-Vahrson modificada.

El caso crítico ocurre en condiciones de suelos saturados, la cual es probable durante los meses de invierno en la cuenca (septiembre-diciembre) y si existe una concentración anómala de precipitación por efecto de una tormenta. En este escenario, solamente un $12 \%$ del área puede catalogarse como estable, ya que más de un $75 \%$ de la cuenca alcanza factores 
de seguridad cercanos a 1,0, pudiendo generar deslizamientos y aumento en los procesos erosivos ya identificados.

Figura 10. Probabilidad de excedencia de la aceleración crítica en las laderas (FS $\leq 1,0)$, en dos sismos o escenarios críticos empleando la metodología PISA.

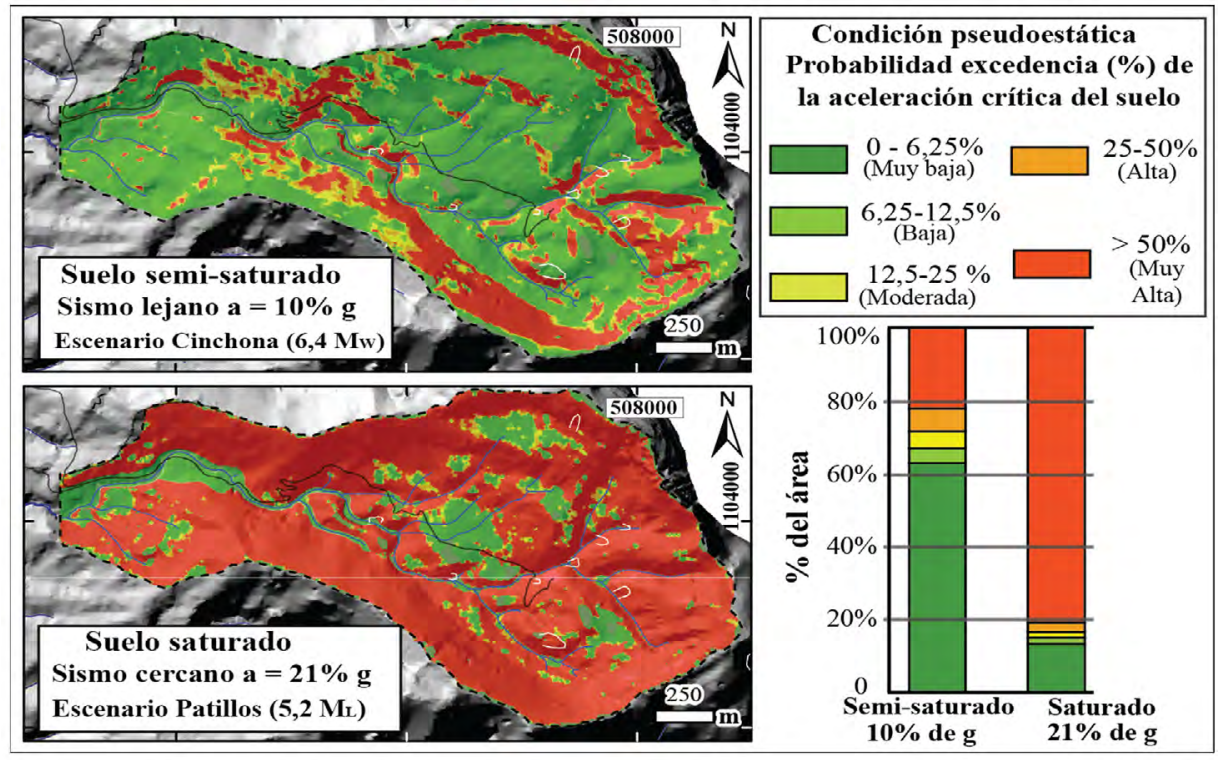

Fuente: Sequeira-Arguedas (2019)

El caso pseudoestático (Figura 10) implica considerar una fuerza externa adicional en las laderas, la cual generalmente se asume paralela al vector de máxima pendiente y cuya magnitud depende de las aceleraciones sísmicas espectrales en el sitio. A pesar de que cualquier escenario sísmico puede modelarse, se consideran dos eventos históricos generados en el arco volcánico de la Cordillera Central.

En el caso del sismo de Cinchona de 2009, considerando una aceleración de $0,98 \mathrm{~m} / \mathrm{s}^{2}$ solamente las áreas de alta pendiente son las que alcanzarían eventualmente inestabilidad, debido al efecto de atenuación sísmica. Cerca de $21 \%$ del área presenta una probabilidad alta de alcanzar un factor de seguridad pseudoestático inferior o igual a 1,0. Se modelaron las condiciones de saturación aproximadas en enero según los registros de precipitación; 
sin embargo, al tratarse de suelos volcánicos estos podrían encontrarse con contenidos de humedad mayores o casi saturados $(\mathrm{Hw} \sim 1,0)$.

En el caso de un sismo cercano con suelo saturado como el de Patillos en diciembre de 1952, el escenario de estabilidad es opuesto, pues cerca de un $82 \%$ del área de la cuenca tiene una probabilidad alta a muy alta de alcanzar la inestabilidad. Esta probabilidad indica que un pixel (de $1,5 \mathrm{~m}$ ) puede tener una probabilidad del $50 \%$ o mayor de deslizarse, según el modelo de falla escogido (talud infinito). Solamente las áreas correspondientes a las terrazas volcánicas y algunos valles fluviales pueden considerarse "estables"; sin embargo, en un análisis integrado por amenaza geológica no es viable considerar estos sitios como poco susceptibles, pues los cauces pueden represarse producto de un sismo intenso o ser propensos a caída de materiales, entre ellos bloques, árboles o suelo inconsolidado. Registros históricos evidencian que la cuenca del río Blanco (4 km al norte del área de estudio) se vio afectada por represamientos y avalanchas durante el sismo de Patillos de 1952 (Montero \& Alvarado, 1995, p. 29-35), por lo que es posible un escenario similar en el área.

\section{Capacidad de arrastre del cauce y su relación con los puentes del corredor vial}

En visitas al campo, se comprobaron bloques rocosos ígneos angulosos y subredondeados, que generan alta rugosidad del cauce, presencia de bancos laterales de deposición y sectores con incisión del cauce en materiales blandos, principalmente arcillas (Figuras 11 y 13).

Inspeccionando los tramos superiores e inferiores a los puentes $1 \mathrm{y}$ 2, se encontraron bloques rocosos cuyas dimensiones superan los claros actuales o altura libre respecto al espejo de agua actual, con lo cual se determina que flujos concentrados de detritos han ocurrido con anterioridad y pueden generarse nuevamente, siendo capaces de movilizar enormes volúmenes de material y dañar seriamente los accesos al sitio, siendo una zona estratégica de producción de lácteos y hortalizas, además de captarse agua para consumo humano.

Durante la actividad eruptiva del volcán Irazú entre 1963 y 1965, por el cauce del río Virilla descendieron lahares que alcanzaron el poblado de San Isidro de Coronado y otros poblados aguas abajo en el mes de septiembre de 1963 (Alvarado, 2011, p. 257). Las subestructuras de los puentes 
son susceptibles por impactos, arrastre hidráulico y oxidación en sus componentes, principalmente el Puente 2, que presenta un estado estructural pobre, con varillas expuestas, apoyos agrietados y vigas corroídas.

El Puente 1 presenta muy buen estado de servicio, pues su estructura de concreto reforzado no presenta agrietamientos ni alteración. La antigüedad de estos puentes es de 50 años y ya han soportado eventos sísmicos (Cuadro 3).

Figura 11. A) Puente 1 en el corredor vial La Holanda, fabricado en concreto reforzado. B) Puente 2 en el corredor vial La Holanda, fabricado en acero, madera y subestructura de concreto reforzado. C) Bloque rocoso anguloso en márgenes del cauce (escala $1 \mathrm{~m}$ ).

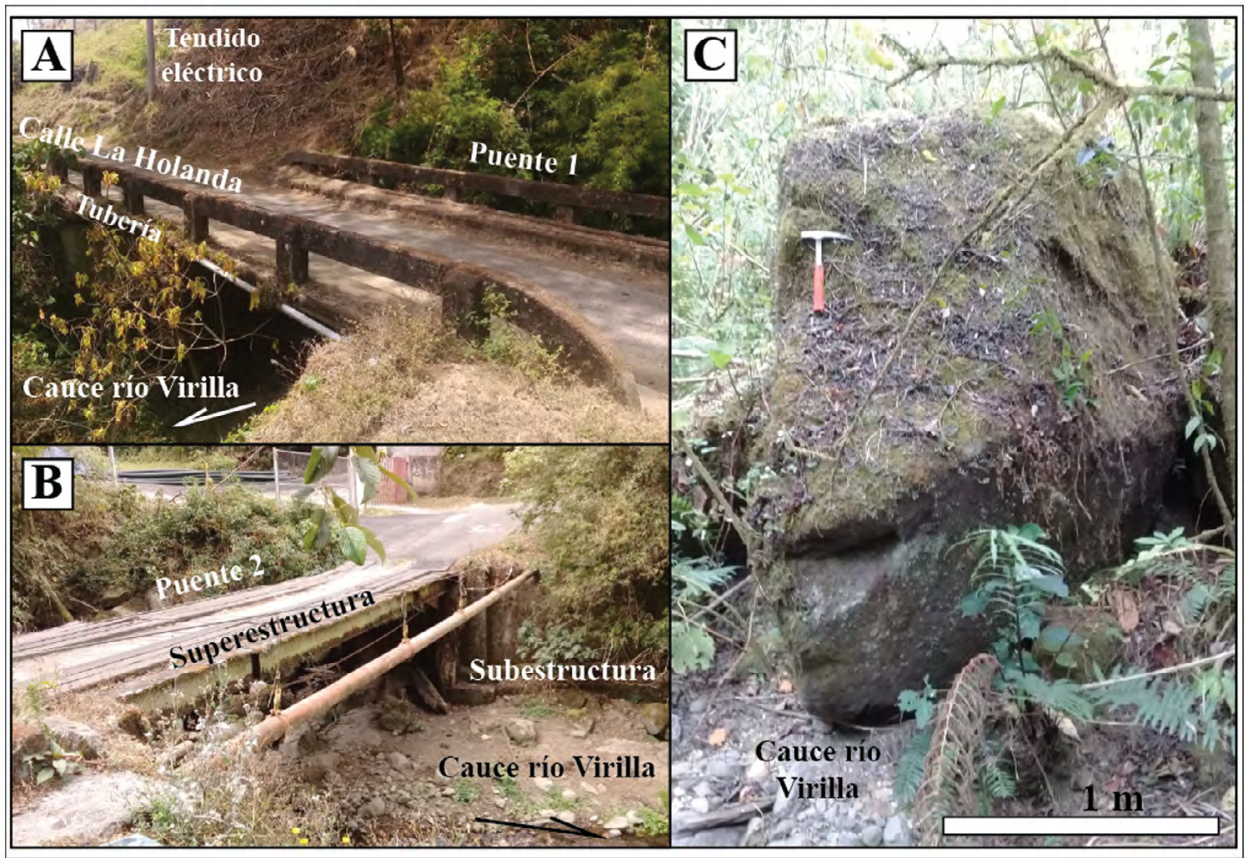

Fuente: Elaboración propia 
Cuadro 3. Especificaciones de los puentes 1 y 2 en el corredor vial La Holanda.

\begin{tabular}{c|c|c|c|c|c}
\hline Puente & Estructura & $\begin{array}{c}\text { Largo } \\
(\mathbf{m})\end{array}$ & $\begin{array}{c}\text { Ancho } \\
(\mathbf{m})\end{array}$ & $\begin{array}{c}\text { Claro } \\
\text { Libre (m) }\end{array}$ & Observaciones \\
\hline Puente 1 & $\begin{array}{c}\text { Superestructura } \\
\text { y subestructu- } \\
\text { ra de concreto } \\
\text { reforzado. }\end{array}$ & 15,7 & 5,8 & 2,8 & $\begin{array}{c}\text { Cimentado en depósi- } \\
\text { tos aluviales, obstruc- } \\
\text { ciones de vegetación. } \\
\text { Buen estado. }\end{array}$ \\
\hline & $\begin{array}{c}\text { Superestructura de } \\
\text { acero y madera. } \\
\text { Subestructura } \\
\text { de concreto } \\
\text { reforzado. }\end{array}$ & 11,8 & 3,1 & 2,5 & $\begin{array}{c}\text { Cimentado en depó- } \\
\text { sitos aluviales. Acero } \\
\text { corroído. Presenta } \\
\text { filtraciones y agrieta- } \\
\text { mientos. Pobre estado } \\
\text { de servicio. }\end{array}$ \\
\hline
\end{tabular}

Fuente: Elaboración propia

\section{Zonificación y recomendaciones de uso}

Considerando la capacidad de arrastre hidráulica, la amenaza sísmica, la susceptibilidad y ocurrencia probabilística de deslizamientos en la cuenca alta del río Virilla, se generó una zonificación integrada (Figura 12), con el fin de determinar cuáles sectores presentarían afectaciones si ocurre un evento sísmico o hidrometeorológico.

En primera instancia se generó una zona inundable (retiro) de todos los cauces de la cuenca con $50 \mathrm{~m}$ de ancho y se determinaron las áreas de alcance por colapso gravitacional y deposición coluvial.

Con la susceptibilidad y estimación del factor de seguridad en las laderas, se discriminaron las áreas sumamente inestables, moderadamente estables y de uso conforme. Las áreas inestables coinciden con las de mayor pendiente y escarpes con reptación, en ellas es recomendable conservar las zonas forestales con el fin de disminuir el potencial erosivo por escorrentía. 
Figura 12. Mapa de zonificación integrado ante amenazas geológicas y uso recomendado en la cuenca alta del río Virilla, considerando escenarios sísmicos críticos y suelo saturado.

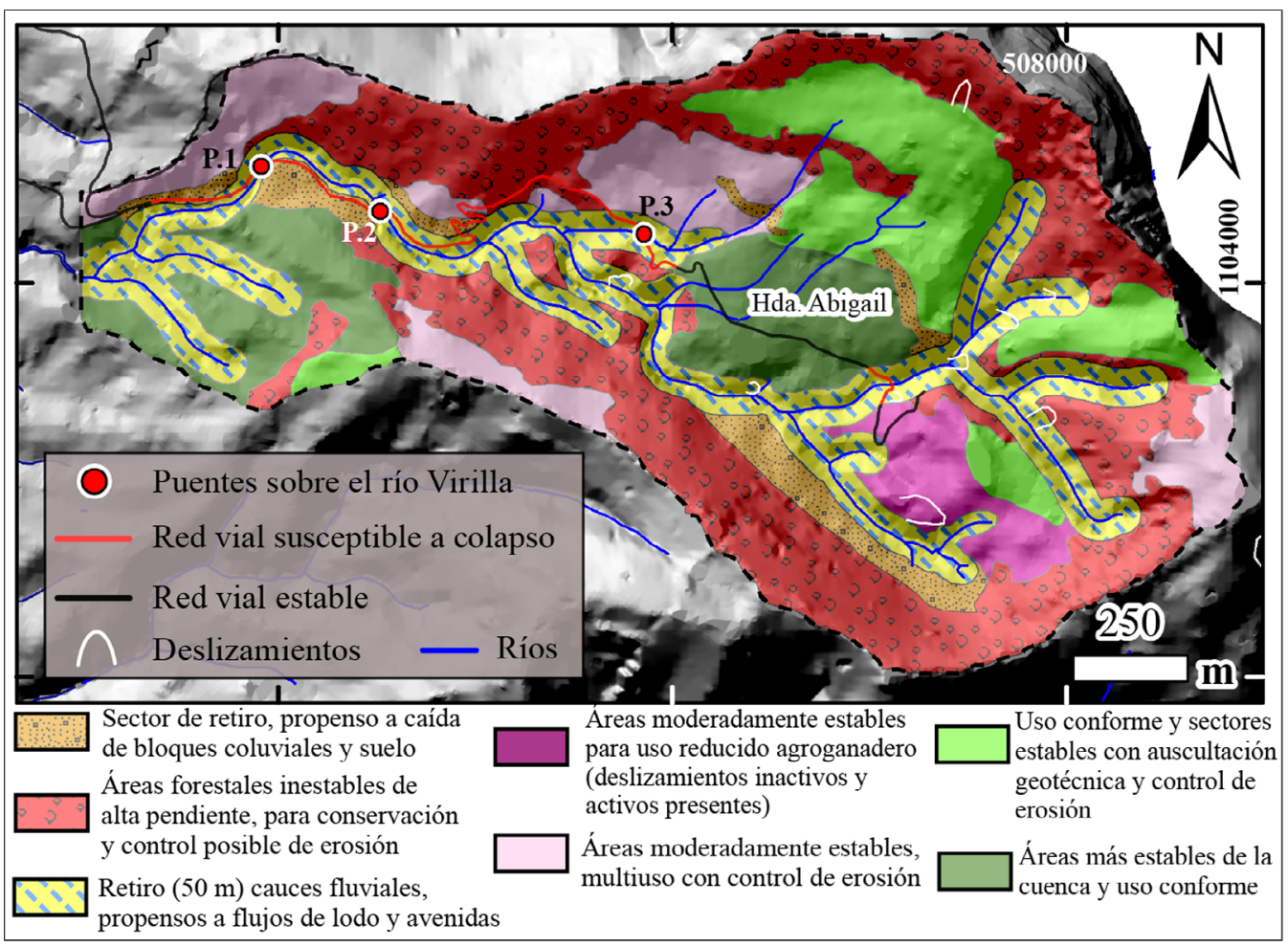

Fuente: Elaboración propia

Las áreas moderadamente estables son escasas y actualmente se dedican a actividades ganaderas; sin embargo, no se recomienda remover zonas forestales, sino más bien controlar la erosión fluvial, de ser posible instrumentar la ladera en lo que respecta a las haciendas productivas. En las áreas de uso conforme se ubica infraestructura habitacional y productiva, representando un $24,6 \%$ del área.

Estos sectores son estables pero pueden presentar algún grado de afectación ante caída de materiales. En el caso del corredor vial La Holanda, se determinó que 2,1 km son susceptibles a colapsar (un 39,6\% del corredor vial), pues presentan socavaciones laterales producto de la acción 
erosiva del río Virilla, depósitos de caída, desprendimientos activos y escasos drenajes pluviales (Figura 13).

Figura 13. A), B) y C) Vista de desprendimientos recientes a lo largo del corredor vial La Holanda que atraviesa el área de estudio, notorio los escasos desagües pluviales. D) Claro vertical de $2,8 \mathrm{~m}$ en el Puente $1 \mathrm{y}$ materiales represados.

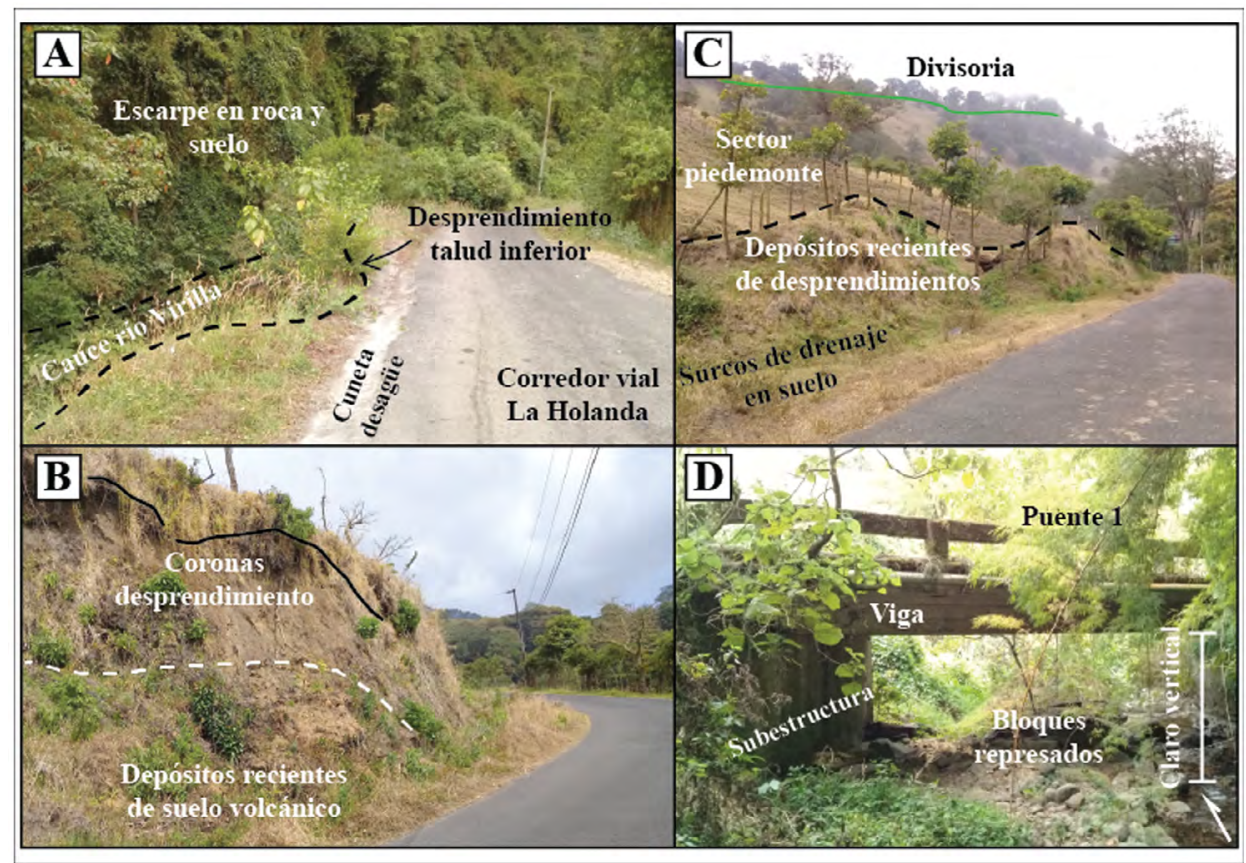

Fuente: Elaboración propia

\section{Conclusiones}

La cuenca alta del río Virilla es el resultado de la evolución de un foco eruptivo antiguo, asociado al volcanismo del Grupo Irazú, cuyas rocas datan del Chibaniano o Pleistoceno Medio (Alvarado et al., 2006, p. 263 y 264) y el modelado por la acción del río Virilla y eventos de colapso activos e inactivos. Predominan laderas de pendientes superiores a $10^{\circ}$, en sectores escarpados donde la erosión es intensa y la inestabilidad es evidente, con presencia de reptación y deposición coluvial en los piedemontes. Esta 
serie de agentes de geodinámica externa ha generado disección, divisorias sinuosas agudas y patrones de drenaje paralelos.

Las metodologías Mora-Vahrson modificada (MVm) y PISA constituyeron un insumo importante en la determinación de la susceptibilidad al deslizamiento en la cuenca así como evaluación probabilística de estabilidad en la ladera, siendo posible complementarlas y modelar diversos escenarios sísmicos y de saturación de suelos. Sin embargo, MVm es útil en estudios a priori y es necesario contar con un modelo geológico detallado. PISA por su parte, trabaja en términos probabilísticos pero requiere de una asignación detallada de unidades geotécnicas (espesores deslizables y parámetros de corte), con la ventaja de que permite incorporar propiedades de resistencia al corte y físicas de los materiales.

Con la integración de factores geológicos evaluados, existe congruencia con el uso actual y las zonas de mayor estabilidad en la cuenca; sin embargo, no implica que no se verán afectadas a futuro ante sismos cercanos y eventos hidrometeorológicos extraordinarios. Un tramo importante $(2,1 \mathrm{~km})$ del corredor vial La Holanda es susceptible a colapsar por desprendimientos de material, flujos de lodo (puentes) y escasos desfogues pluviales. Es necesario conservar la cobertura forestal para disminuir el potencial erosivo por escorrentía.

\section{Referencias}

Alvarado, A., Mata, R. \& Chinchilla, M. (2014). Arcillas identificadas en suelos de Costa Rica a nivel generalizado durante el período 19312014: I. historia, metodología de análisis y mineralogía de arcillas en suelos derivados de cenizas volcánicas. Agronomía Costarricense, 38 (1), pp. 75-106.

Alvarado, G. E. (1993). Volcanology and petrology of Irazú volcano, Costa Rica. Kiel University, Germany.

Alvarado, G. E. (2011). Costa Rica: Land of volcanoes San José: Editorial Universidad Estatal a Distancia, p. 257.

Alvarado, G. E., Carr, M. J., Turrin, B. D., Swisher, C, Schmincke, H. \& Hudnut, K. (2006). Recent volcanic history of Irazú volcano, Costa Rica: Alternation and mixing of two magma batches, and pervasive mixing. Geological Society of America Special, 2412(14), pp. 259-276. 
Barrantes, G., Barrantes, O. \& Núñez, O. (2011). Efectividad de la metodología Mora-Vahrson modificada en el caso de los deslizamientos provocados por el Terremoto de Cinchona, Costa Rica. Revista Geográfica de América Central, 47, pp. 141-162.

Bergoeing, J. P. (1979). Geomorfología del sector volcánico Las NubesCabeza de Vaca. San José, Costa Rica.

Carrillo, F. (2019). Microzonificación geotécnica de la Finca Castro, Santa Ana, San José: determinación probabilística de ocurrencia de deslizamientos en suelos de material tipo bloques en matriz. Tesis Licenciatura. Escuela de Geología, Universidad de Costa Rica, p. 176.

Denyer, P., \& Arias, O. (1991a). Estratigrafía de la región central de Costa Rica. Revista Geológica de América Central, 12, 1-59. https:// doi10.15517/rgac.v0i12.13039

González de Vallejo, L., Ferrer, M., Ortuño, L., \& Oteo, C. (2002). Ingeniería Geológica Madrid: Pearson Educación, pp. 447-448.

Granados, R. (2013). Determinación de la probabilidad de ocurrencia de deslizamiento en suelos derivados de cenizas volcánicas, Mansiones, San Rafael, Montes de Oca, Costa Rica (Tesis Licenciatura). Escuela de Geología, Universidad de Costa Rica, p. 203.

Grandes masas se desprendieron del macizo Irazú y aparecen como cerritos en la región de Patillos. (1953, January 7). La Nación, p. 6.

Griffiths, D., Huang, J. \& Fenton, G. (2011). Probabilistic infinite slope analysis. Computers and Geotechnics, 38, pp. 577-584. Recuperado de: doi:10.1016/j.compgeo.2011.03.006

Haneberg, W. (2004). A rational probabilistic method for spatially distributed landslide hazard assessment. Environmental \& Engineering Geoscience, 10, pp. 27-43. 10.2113/10.1.27

Haneberg, W. (2005). PISA: Probabilistic Infinite Slope Analysis. User Manual. California: Haneberg Geoscience.

Henríquez, C., Cabalceta, G., Bertsch, F., \& Alvarado, A. (2014). Principales suelos de Costa Rica. Recuperado el 17 de mayo de 2020, de http://www.mag.go.cr/ bibioteca_virtual_ciencia/suelos-cr.html

Hidalgo, P., Alvarado, G. E. \& Linkimer, L. (2004). La lavina del Valle Central (Costa Rica): ¿Lahar o debris avalanche? Revista Geológica de América Central, 30, 101-109. https://doi.org/10.15517/rgac. v0I18.13522 
Instituto Geográfico Nacional. (2007). Mosaico de Ortofotos 1:5000 (Costa Rica). Recuperado el 17 de mayo de 2020, de https://geos.snitcr. go.cr/be/IGN_5/wfs?

Instituto Geográfico Nacional. (2008). Hoja Río Durazno (3445-IV-1), Costa Rica, escala 1: 10 000. Recuperado el 17 de mayo de 2020, de https://www.mivah.go.cr/PRUGAM_Cartografia_Cuadrantes_Nor_ Este.shtml

Instituto Meteorológico Nacional. (2019). Datos climáticos estaciones Rancho Redondo, Coronado, Irazú, Aranjuez, La Palma y Llano Grande (de 1948 a 2018). San José, Costa Rica.

Instituto Tecnológico de Costa Rica. (2014). Atlas de Costa Rica, 2014. Recuperado el 117 de mayo de 2020, de https://repositoriotec.tec. ac.cr/handle/2238/6749? show =full

Jiménez, D., Cerdas, A., \& Salazar, J. (2014a). Geomechanical classification of conglomerates for the Térraba and Limón Sur basins, Costa Rica. In Rock Mechanics for Natural Resources and Infrastructure. Goiania, Brazil: ISRM.

Jiménez, D., Gómez, C., Arquín, F., Salazar, J., \& Cerdas, A. (2014b). Geomechanical characterization for the Doán Formation breccias, Siquirres, Costa Rica. In Rock Mechanics for Natural Resources and Infrastructure. Goiania, Brazil: ISRM.

Krushensky, R. (1972). Geology of Istarú quadrangle, Costa Rica. U.S. Geol. Surv., Bull., 1358, 46 p.

Kussmaul, S. (2000). Estratigrafía de las rocas ígneas. En P. Denyer \& S. Kussmaul (Eds.), Geología de Costa Rica. Cartago: Editorial Tecnológica de Costa Rica, pp. 63-86.

Linkimer, L. (2003). Neotectónica del extremo oriental del Cinturón Deformado del Centro de Costa Rica. Universidad de Costa Rica.

Linkimer, L. (2008). Relationship between peak ground acceleration and Modified Mercalli Intensity in Costa Rica. Revista Geológica de América Central, 38, pp. 81-94.

López, C., Mataix, C., Fariñas de Alba, J. L., Llopis, G., Serrano, P., García, P., \& Gómez, R. (2008). Manual de estabilización y revegetación de taludes. Madrid: Editorial U.D. Proyectos. 
Mata R., Rosales A., Vásquez A. y Sandoval, D. (2013). Mapa de Órdenes de Suelos de Costa Rica. 2 ed. San José, Costa Rica. Asociación Costarricense de la Ciencia del Suelo. Escala 1: 200.000. Color.

Ministerio de Obras Públicas y Transporte. (2019). Red Vial Nacional de Costa Rica 1:1000 y 1:5000. Recuperado el 17 de mayo de 2020, de https://geos.snitcr.go.cr/be/IGN_MOPT/wfs?

Montero, W., \& Alvarado, G. E. (1995). El Terremoto de Patillos del 30 de diciembre de $1952(\mathrm{Ms}=5,9)$ y el contexto neotectónico de la región del volcán Irazú, Costa Rica. Revista Geológica de América Central, 18, pp. 25-42. Recuperado de: https://doi.org/10.15517/ rgac.v0I18.13522

Montero, W., Lewis, J., Marshall, J., Kruse, S. \& Wetmore, P. (2013). Neotectonic faulting and forearc sliver motion along the Atirro-Río Sucio fault system, Costa Rica, Central America. Geologic Society of America Bulletin, 125(5-6): pp. 857-876. Recuperado de: https:// doi.org/10.1130/B30471.1

Mora, R. (1998). Propiedades físicas, hidráulicas y mecánicas de suelos de origen volcánico, en sitios seleccionados del Valle Central, Costa Rica. Revista Geológica de América Central, 19, pp. 81-98. Recuperado de: https://doi.org/10.15517/rgac.v0i22.8602

Mora, R. (2010). Estabilidad en condiciones estáticas y probabilidad de ocurrencia de deslizamientos en condiciones pseudoestáticas de las laderas del Bajo Los Anonos, San Rafael, Escazú, San José. Revista de Ingeniería, 20, pp. 41-49.

Mora, R., Chávez, J., \& Vázquez, M. (2002). Zonificación de la susceptibilidad al deslizamiento: Resultados obtenidos para la península de Papagayo mediante la modificación del método Mora \& Vahrson (Mora et al., 1992). En III Curso internacional sobre Microzonificación y aplicación en la mitigación de desastres. Lima, pp. 38-46.

Mora, R., Mora, S., \& Vahrson, W. (1992). Mapa de amenaza de deslizamientos, Valle Central, Costa Rica. San José: Centro de Coordinación para la Prevención de Desastres Naturales en América Central.

Obando, L. (2004). Mega-rasgos geomorfológicos del modelo de elevación digital, asociados al volcán Barva. Revista Geológica de América Central, 31, pp. 81-86. 
Peraldo, G., \& Montero, W. (1999). Sismología histórica de América Central México D.F.: Editorial Instituto Panamericano de Geografía e Historia, pp. 225-227.

Quesada \& Feoli (2018, p. 34). Comparación de la metodología MoraVahrson y el método Morfométrico para determinar áreas susceptibles a deslizamientos en la microcuenca del río Macho, Costa Rica. Revista Geográfica de América Central, 61, pp. 17-45.

Quirós, D. (2019). Análisis de estabilidad de laderas en los distritos de Escazú y San Antonio del cantón de Escazú: Una contribución para una futura gestión del riesgo. Tesis Licenciatura. Escuela de Geología, Universidad de Costa Rica, p. 178.

Rodríguez, E., Linkimer, L. \& Montero, W. (2019). Neotectónica de la falla Cipreses. Boletín de Geología, 41(2), 15-33. Recuperado de: http://dx.doi.org/10.18273/revbol.v41n2-2019001.

Segura, G., Badilla, E. \& Obando, L. (2011, p. 106-114). Susceptibilidad al deslizamiento en el corredor Siquirres-Turrialba. Revista Geológica de América Central, 45, pp. 101-121.

Sequeira-Arguedas, J. (2019). Estimación de la ocurrencia de deslizamientos a partir del método PISA y Mora-Vahrson modificado en el cerro Pico de Piedra y cuenca alta del río Virilla. Comunicación presentada en el III Congreso Geológico, San José, Costa Rica. 10.1 3140/RG.2.2.32525.28649

Sistema Nacional de información Territorial. (2017). Costa Rica. Mosaico de Ortofotos 1:5 000, 2017. Recuperado el 17 de mayo de 2020, de https://geos1.snitcr.go.cr/Ortofoto2017/wms?VERSION=1.1.1

Vargas, A. (1994). Evaluación de características químicas de aguas superficiales e hidrogeológicas en las subcuencas parte alta río Virilla y río Durazno, cantón Vázquez de Coronado. Tesis Licenciatura. Escuela de Geología, Universidad de Costa Rica, p. 237. 